\title{
Does early intervention 'work'?
}

Proponents of American Head Start programmes in the 60 s and early 70 s promised boldly that preschool attendance would increase the intelligence, school attainment, and self concept of disadvantaged children. Similar optimism lay behind the British Educational Priority Area programmes that were aimed at eradicating social inequality by helping children from poor families to participate at school on an equal footing with their more privileged peers. ${ }^{1}$ The first wave of evaluation studies on both sides of the Atlantic was so cheering that optimism reigned for several years. Then came the disappointing 'wash-out' research, notably the Westinghouse study showing a grim picture of 'extra' skills which disappeared three to four years after children left the preschool. ${ }^{2}$

There was much pessimism about early education until a group of American researchers began a rigorous study of the long term effects of compensatory education. ${ }^{3}$ They ignored 'garden variety' programmes (which excluded most of the federally funded Head Start) and focused instead on intervention projects that employed rigorous research designs. Lazar et al limited the follow up study to the effects of preschool projects with sample size greater than 100 children, which employed quantitative assessment measures, comparison or control groups, and follow up after children entered school. By these strict criteria 11 carefully monitored programmes were chosen for follow up study. Approximately 2000 preschool 'graduates' were tracked down in adolescence and researchers investigated their school and employment records, as well as interviewing their families.

Results showed clearly that attendance at excellent, cognitively orientated preschool programmes was associated with later school competence. More specifically, preschool graduates were less likely to be assigned to 'special' schools or to be retained in grade. At interview, researchers found that preschool graduates were more likely than controls to give achievement related answers to the invitation 'tell me something you've done that made you feel proud'. The interviews with children and parents showed that early education affected the achievement orientation of the entire family, giving the child confidence in his own self efficacy. ${ }^{4}$

The most carefully controlled of all 11 programmes reviewed by Lazar et al was the High/Scope project. ${ }^{5}$ The table summarises the main findings on 123 children who were followed up to the age of 19. A sophisticated cost-benefit analysis was carried out and it showed that 'for every $\$ 1000$ that was invested in the preschool programme, at least $\$ 4130$ (after inflation) has been or will be returned to society'. ${ }^{6}$ These calculations were based on the financial cost to society of juvenile delinquency, remedial education, and joblessness-set against the running costs of an excellent preschool programme.

Although American studies cannot prove that all preschool programmes will cause lasting improvements, they do demonstrate that early education can

Table Major findings at age 19 in the High/Scope study $(n=123)^{\prime}$

\begin{tabular}{|c|c|c|c|}
\hline \multirow[t]{2}{*}{ Category } & \multicolumn{3}{|l|}{ Group } \\
\hline & $\begin{array}{l}\text { Attended } \\
\text { preschool }\end{array}$ & $\begin{array}{l}\text { Did not } \\
\text { attend } \\
\text { preschool }\end{array}$ & $p$ Value \\
\hline $\begin{array}{l}\% \text { Employed }(n=121) \\
\% \text { High school graduate }\end{array}$ & 59 & 32 & $0 \cdot 032$ \\
\hline$\%$ With college or vocational training $(n=121)$ & 38 & 21 & 0.029 \\
\hline$\%$ Ever detained or arrested $(n=121)$ & 31 & 51 & 0.022 \\
\hline Females only: teen pregnancies/100 $(n=49)$ & 64 & 117 & $0 \cdot 084$ \\
\hline \multicolumn{4}{|l|}{ Functional competence } \\
\hline (APL survey: possible score 40$)(n=109)$ & $24 \cdot 6$ & $21 \cdot 8$ & $0 \cdot 025$ \\
\hline$\%$ Of years in special education $(n=112)$ & 16 & 28 & 0.039 \\
\hline
\end{tabular}


change the course of children's lives. ${ }^{7}$ Furthermore the High/Scope study strongly suggests that the mechanism for increasing school competence and employment is the child's positive attitude towards achievement and parents' increased aspiration for their offspring. The vigour of the American research, coupled with a plausible theoretical model, justifies optimism about cognitively structured programmes. But do they affect all children equally? The most recent research on Head Start in the United States suggests that the children who benefit most from preschool are those from the most disadvantaged backgrounds. ${ }^{8}$

There is less longitudinal research in Britain. The massive Child Health and Education (CHES) study gives cause for concern by showing great variation in the social backgrounds of children who attend different forms of provision; the better off go to playgroup and the most disadvantaged attend day nursery. ${ }^{9}$ McGuire and Richman have documented greater severity of behaviour problems in the day nursery population, when compared with many nursery schools or playgroups. The CHES study has shown that children who attend day nursery go on to careers as poor readers and mathematicians in school.

The picture is now fully drawn: (a) educationally oriented preschool programmes can prevent cognitive and behavioural problems later in life ${ }^{11}$; (b) the children most at risk of behavioural and intellectual problems attend day care provision; and (c) there is an urgent need to improve educational provision in day nurseries if the 'life chances' of so many disadvantaged children are to be improved. ${ }^{12}$

\section{References}

1 Smith G, James T. The effects of preschool education: some American and British evidence. Oxford Review of Education 1975;1:233-40.

2 Westinghouse Learning Corporation. The impact of Head Start: an evaluation of Head Start on children's cognitive and affective development. Report prepared for the Office of Economic Opportunity, 1969. (Contract B89-4536.) (Westinghouse study.)

${ }^{3}$ Lazar I, Darlington R, Murray H, Royce J, Snipper A. Lasting effects of early education: a report from the consortium for longitudinal studies. Monographs of the Society for Research in Child Development 1982;47:2-3 (Serial No 195).

${ }^{4}$ Rutter M. Family and school influences on cognitive development. J Child Psychol Psychiatry 1985;26:683-704.

5 Berrueta-Clement J, Schweinhart LJ, Barnett WS, Epstein AS, Weikart DP. Changed lives: the effects of the Perry preschool programme on youths through age 19. Monographs of the High/Scope Educational Research Foundation 1984, No 8.

- Breedlove C, Schweinhart LJ. The cost-effectiveness of high quality early childhood programs. A report for the 1982 Southern Governors' Conference, South Carolina, 1982.

7 Woodhead M. Preschool education has long term effects but can they be generalised? Oxford Review of Education 1985;11: 133-56.

${ }^{8}$ Lee V, Brooks-Gunn J, Schnur E. Does Head Start work? Developmental Psychology 1988;24:210-22.

9 Osborn AF, Milbank JE. The effects of early education. Oxford: Clarendon Press, 1987.

${ }^{10}$ McGuire J, Richman N. The prevalence of behaviour problems in three types of preschool group. J Child Psychol Psychiatry 1986;27:455-72.

11 Offord DR. Prevention of behavioural and emotional disorders in children. J Child Psychol Psychiatry 1987;28:9-19.

12 Education, Science and Arts Committee. Educational provision for the under fives. London; HMSO, 1989.

K SYLVA

Department of Education, University of Warwick, Coventry CV4 $7 A L$ 